\title{
PREPARATION AND BARRIERS IN IMPLEMENTATION INTEROPERABILITY SYSTEMS AMONG HOSPITALS: A SYSTEMATIC REVIEW
}

\author{
Meutia Arini Yasrizal ${ }^{1 *}$ and Wiku Bakti Bawono Adisasmito ${ }^{2}$ \\ ${ }^{1}$ Hospital Administration, Department Faculty of Public Health Universitas Indonesia, Indonesia \\ ${ }^{2}$ Health Policy and Administration Department Faculty of Public Health Universitas Indonesia, Indonesia
}

\begin{abstract}
Hospital Information System must provide innovative services in digitals era. The interoperability systems made data interconnected between hospitals, health services and the ministry of health. This system is urgently needed to improve National health services. The aim of the study to assess the preparation, barriers and benefit of interoperability system implementation. The study was a systematic review of journal articles by assessing several databases, from Pubmed, Proquest, EBSCO, and Springer Link to identify relevant studies with PRISMA. The keyword is "Health Information Interoperability, Hospital and Implementation". Ten articles were obtained which matched the inclusion and exclusion criteria. These articles explained how the system can be applied, from the preparation of the infrastructure, such as the standard systems that have been adopted, Fast Healthcare Interoperability Resources (FHIR) from Health Level 7 (HL7). The barriers were the standardized data between hospitals with same vendors, so the hospitals were reluctant to implement it. The benefit was the hospital services improve quality in accuracy, legibility, completeness and consistency of documents. Hoped that interoperability can make health information systems more effective by preventing repeated examinations and so that can reduce health costs. This system is a big challenge throughout the world, the role of government and policymakers is needed in implementation.
\end{abstract}

Keywords: Health Information Interoperability, Hospital, Implementation, Systematic Review

\section{Introduction}

Information and communication technology are increasingly developing in the health sector, especially in health services. Health care is a continuous process based on information and communication, which requires constant interaction and exchange of information between the stakeholders, doctors or hospitals as service providers and patients, as well as insurers such as insurance and the state. (WHO et al., 2013) recognizes e-health as a costeffective and safe use of IT in health services, education and research in the health sector.

Hospital information systems (HIS) must provide innovative services in digitals era, like Electronic Medical records (EMR)/Electronic Health Records (EHR) in the hospital. EHR is an innovation in the health system that aims to increase the efficiency and quality of health services provided. (Poba-Nzaou et al., 2020). Some countries are still reluctant to implement EHR, due to fear of data security. Comprehensive electronic medical records are the basis of good service quality. Clinicians need these records for recording and making clinical decisions, for auditing and providing quality service, and for professional regulation and re-validation (HIMSS, 2014).

Software, medical devices and IT systems used in healthcare organizations are often incompatible, making it difficult to exchange patient data, requiring time and cost. In accordance with (Shull, 2019) due to the lack of knowledge about interoperable EHR, most countries have systems that cannot combine information about the entire population. Even in one city or region, the software used in the hospital does not match each other, even though used the same vendor. So that this interoperability system cannot be implemented. 
Interoperability according to HIMSS (2013) has a broad meaning, namely the ability of two or more systems to exchange information and to use information that has been exchanged. So that health information systems can work together in crossing organizational boundaries in advancing the delivery of effective health services for individuals and communities. This interoperability is one of the prerequisites in a health information system which reduces unnecessary waste of money, errors, delays and redundant checkups.

Alarakhia, et al (2018) Interoperable EHR in Canada increasingly provides individual patients with a secure and private record of their health history. Provide benefits to the community such as quality of care, public health benefits, optimal practice space and care coordination. In accordance with (Dobrow et al., 2019) research regarding interoperable EHR and HIE which states that productivity and quality are the two highest dimensions in their assessment. Quality care categories such as care coordination and clinical decision support are the most in demand. For the dimensions productivity, efficiency in the clinical process, time and cost savings that are the expectations of users. User satisfaction also increases when the user can have access to the integrated technology.

By achieving interoperability in the health sector, many benefits will be achieved, such as the quality and safety of patient medical records that are electronic, comprehensive and up to date, as well as an important tool in providing integrated health services. There are several previous studies that have proposed approaches in solving this interoperability challenge. The research objective of this systematic review method is to assess the preparation in implementing the interoperable system between hospitals, by assessing the barriers to its application, and the benefits of implementing this system.

\section{Method}

\section{Information Sources and Data Search}

This study used the Preferred Reposting Items for Systematic Review and Meta-Analysis (PRISMA) method. Keyword selection of medical subjects (Mesh) from Pubmed including subheadings, type of publication, and additional concepts used to identify the term "Health Information Interoperability". This Systematic Review was carried out using an online electronic search engine from 4 databases, including 1) Pubmed, 2) Proquest, 3) EBSCO and 4) Springer Link. The keywords were "Health Information Interoperability AND Hospital AND Implementation".

\section{Eligibility Criteria}

Data were filtered using inclusion criteria, namely: 1) original research, reviews, and consensus statements which explain the interoperability in hospitals in terms of barriers to implementation and benefits obtained after implementation so that the interoperability system increased the quality of health services. 2) The location of interoperability at the hospital, 3) Published between 2010 - 2020, 4) Written in English, 5) the complete article accessed freely (free of charge) (free full text), 6. There is no duplication. The exclusion criteria were any studies that did not match the inclusion criteria above. Additional studies were identified by snowballing the list of references in the full article that matched the inclusion and exclusion criteria.

\section{Selection of Sources of Evidence}

Keywords were used in each database, then explored the research title, abstract and results. The title and abstract fit the inclusion criteria, followed by reading the full article. The author also refined the snowballing references obtained from complete articles matched with inclusion criteria. Starting from reading the research title, abstract and article content according to the description. After the article screening has been completed, the first author 
will explain to the second author and do the second review and discussion. Finally, the first and second authors reach an agreement on the results.

A full article about hospital interoperability system, in terms of system preparation, barriers to implementation and benefits and impacts in its application. We created a table containing the data: author's name and year of publication, research title, location, objectives, and results. Then, we conducted an extraction of variables and independently mapped each eligible article and discussed the results. The data are grouped according to the research objectives, namely preparation for implementation, implementation barriers and benefits.

\section{Charting Data and Data Items}

The author performed data grouping according to before implementation and after the application of interoperable systems between hospitals. Assessed in the application, such as the obstacles in its application and the results after it. A critical review is conducted of existing sources.

\section{Result}

\section{Selection Study}

A preliminary search using keywords found 490 articles from Proquest, 19 articles from EBSCO, 73 articles from Pubmed, and 355 articles from Springer Link. The total number of articles obtained was 937 articles. Then the articles were assessed about duplication from all the databases. There were 17 duplicate articles. Then assessed the inclusion and exclusion criteria and systematic review were not included, 873 articles were not included. 47 articles met the inclusion criteria. Furthermore, an assessment of the eligibility criteria was carried out by assessing the article checklist. There were 10 articles in accordance with the critical appraisal assessment. This article will be examined further.

\section{Study Characteristics}

Of the 10 articles analyzed, there were 4 articles discussed the planning and preparation of the system, 4 articles discussed its implementation, 6 articles discussed the problems and obstacles that occur during its implementation, and 3 articles discussed the benefits obtained after implementation of the system, either for patients, doctors, or hospital 


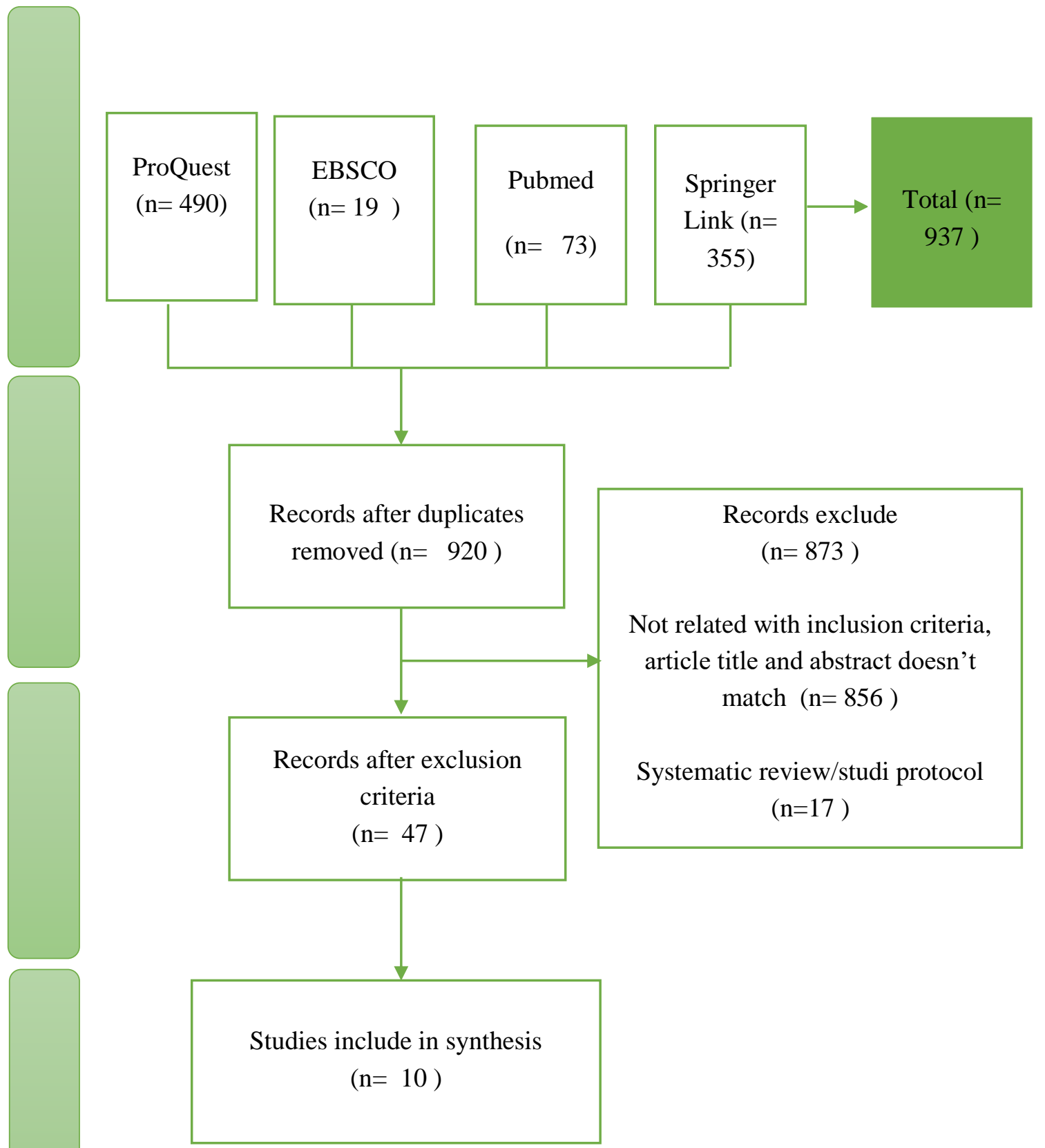

Figure 1. PRISMA- Flow Diagram of study selection 
Table 1. Health Information Interoperability in the Hospital

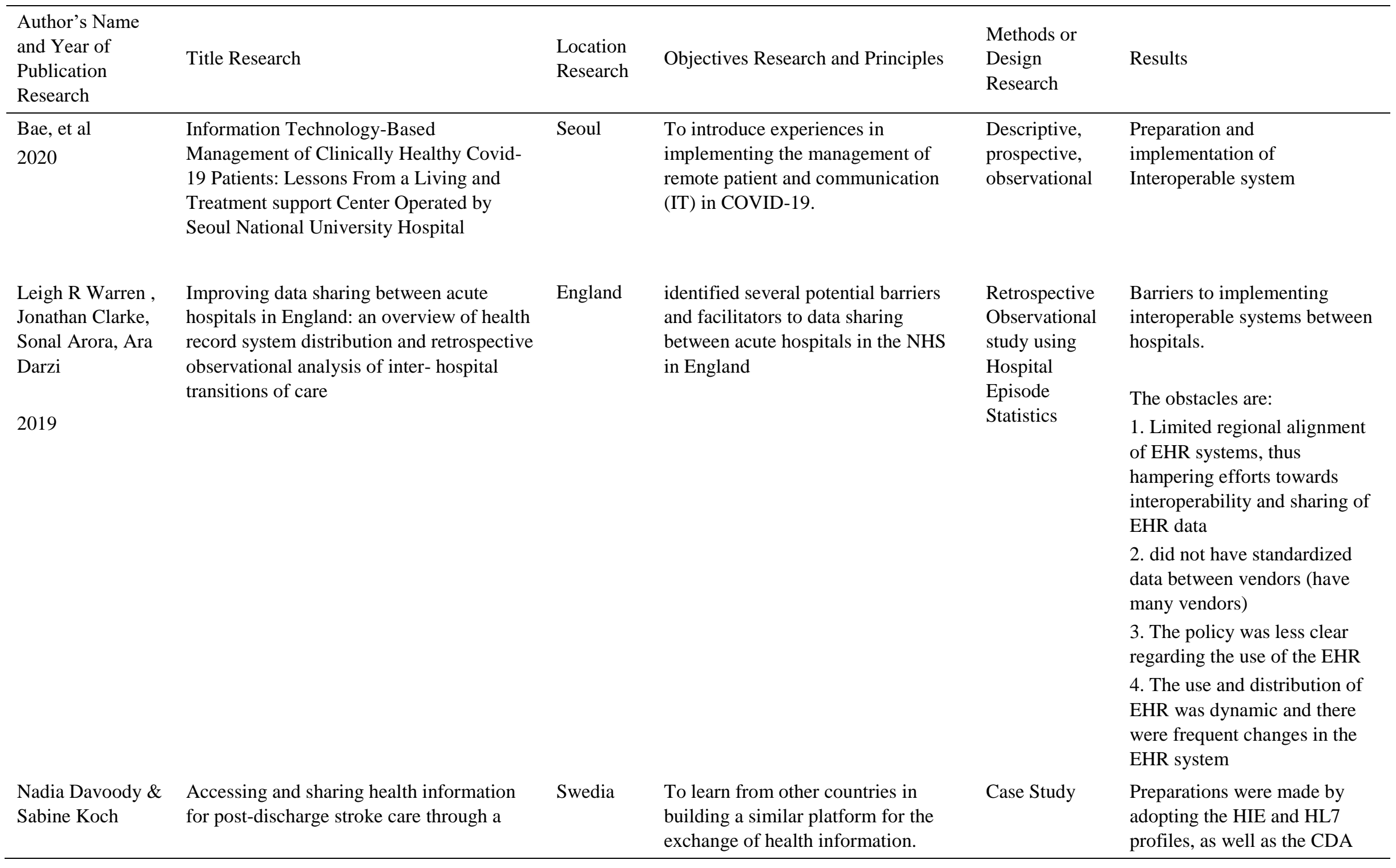




$\begin{array}{ll} & \text { national health information exchange } \\ \text { platform - a case study }\end{array}$

Naomi Muinga, et

al

2020

Jong-Yi Wang,et

al

2017

Madalina Elena

RAC patient record exchange: discrepancies and patient

Interoperability of Medical Data From Concept to Application
Digital health Systems in Kenyan Public Hospitals: a mixed-methods survey
Kenya

\section{Treatment and rehabilitation} planning, to explore opportunities and limitations in accessing and using health information through the national HIE (hospital information exchange) platforms in Sweden

To provide an overview of the fastgrowing digital health systems in Kenya and other regions by sharing knowledge

Attitudes toward inter-hospital electronic among physicians, medical record staff,

To understand the attitudes between different users (doctors, medical record staff and patients) in the aspect of EHR data exchange between hospitals.

Rumania Presenting the interoperable system application proposal and the used as clinical services, with

the Green HL7 CDA

methodology.

The benefits of HIE are interoperable

Mix Methods Interoperable Application Survey

System in Kenya in standardizing data

The survey

was conducted Barriers to its application,

by County

Health namely problems that arise from users, vendors and

Records system interoperability.

Information

Officers

(CHRIO) and

interviewed

digital health

systems

vendors

Cross sectional

Problems in implementing interoperability

379 valid

samples: 155

physicians, 28

MRS, and 196 patients.

Case study

Preparation in the application of Interoperable and 
2015

$\begin{array}{lll} & & \\ \text { Kanakubo } & \text { Comparing the Trends of Electronic Health Japan and } \\ \text { Kharrazi } & \begin{array}{l}\text { Record Adoption Among Hospitals of the } \\ \text { United States and Japan }\end{array}\end{array}$

\section{\& Hadi Kharrazi}

2019 advantages of implementing this

system

To assess the trend of Electronic Health Record (EHR) adoption between hospitals in Japan and the United States

Presenting an overview of the application model of Interoperability in Romanian private hospitals

\section{RAC-ALBU,}

A Model of Achieving Safe Interoperability Romania

Medical Data in the Private Sector of

ALBU

2019

Hsyien-Chia Wen,

et al

2019

Shefali Oza, et al

2017

\section{Health Care in Romania}

An Assessment of the Interoperability of Electronic Health Record Exchanges

Among Hospitals and Clinics in Taiwan

Development and Deployment of the OpenMRS-Ebola Electronic Health Record System for an Ebola Treatment Center in Sierra Leone
Taiwan

Analyzed the efficiency of data exchange and provides suggestions for future developments.

West

Africa :

Sierra

Leone
To describe the work in rapid development and deployment of OpenMRS - Ebola that had already applied. Used as a recommendation for future health emergencies.
Interoperability benefits of

medical data

$\begin{array}{ll}\begin{array}{l}\text { Cross } \\ \text { Sectional by } \\ \text { assessing } \\ \text { statistical } \\ \text { surveys in } \\ \text { 2008, 2011 } \\ \text { and 2014 in }\end{array} & \begin{array}{l}\text { Barriers and Challenges in } \\ \text { and U.S }\end{array} \\ \text { Japan and the } & \\ \text { U.S } & \\ \text { Case Study } & \begin{array}{l}\text { Interoperabel preparation in } \\ \text { data standardization }\end{array} \\ & \begin{array}{l}\text { Advantages in implementing } \\ \text { interoperable systems }\end{array} \\ \text { Research } & \begin{array}{l}\text { Interoperable System } \\ \text { Objects of }\end{array} \\ \text { Preparation and Its Benefits } \\ \text { Cohort Study } & \begin{array}{l}\text { Preparation strategy in } \\ \text { implementing open MRS- }\end{array} \\ & \begin{array}{l}\text { Ebola for interoperability by } \\ \text { standardizing data using } \\ \text { SNOMED CT, ICD-10 and } \\ \text { complying with HL-7 version }\end{array} \\ & \text { 2 \& FHIR }\end{array}$




\section{Study Search Results}

The search articles from the studies conducted were all grouped into the hospital interoperability table, as shown in table 1 .

\section{Synthesis of Results}

Based on ten articles obtained from the results of the synthesis search, it can be seen that the planning and preparation stage of this interoperable system has several stages according to (Oza et al, 2017) (Wang, et al, 2015), namely the stages in the development of the new system must be carried out by pre-development stages, determining: 1) identification of the main needs, such as location or place, 2) identification of software, with standardized data platform using SNOMED CT, ICD-10 and in accordance with HL-7 version 2 \& FHIR for Interoperable data, as for other data by HL-7, CDA and DICOM, 3) Identification of Resources, both human and funds needed in preparation. 4) form a team and design a concept/template. In addition, there are also stages in creating an interoperable flow, namely creating a special server for data and information exchange accessed directly using the Cloud Computing-based Healthcare Information System, converting clinical content stored in local EMR format operated semantically. Among all frameworks/platforms. Adopting the Extensible Markup Language (XML) technique, creating data security by making an agreement with the sign frame/platform by adopting the Extensible Markup Language (XML) technique. The data security stage was carried out by making an agreement with a digital signature and encrypted timestamp, as a verification seal and an encrypted XML document with a time stamp.

Based on the literature, the application of this interoperable system requires identification and clinical data of patients in the form of EHR, as well as data standardization to exchange of medical data between hospitals. According to (Wen, et al, 2019) (Muinga, et al, 2020) that this application requires data exchange between health services in the form of EHR and standardized HL7/CDA R2 data and Digital Imaging and Communication in Medicine (DICOM) for clinical documents, as well as cooperation with the government (Muinga, et al, 2020) (Dovody, et al, 2019) As in Kenya, the pattern of application is carried out by top-down and bottom-up approaches, the top-down approach fostered by the MOH (ministry of health) in the development of open source systems such as OpenMRS; and a bottom-up approach adopted by several small hospitals, using locally developed commercial systems. Sweden created a national HIE platform for the implementation of this interoperable system by adopting standardization of HL7 and CDA data.

Obstacles when implementing this system, according to (Oza, et al, 2017) (Warren, et al, 2019) (Kanakubo, et al, 2019) (Muinga, et al 2020) (Wang, et al 2015), get good problems from user, vendor, and system, namely from the user obtained:

1. difficulties in using the system, due to limited and inadequate training,

2. infrastructure limitations in the event of a power cut, the system cannot operate. And if there is damage in equipment, where the infrastructure is limited as well

3. limited human resources, where the technology capabilities of the staff are still lacking

4. system support, that is, the integrated system is not maximized

5. A long time to download data and images.

Problems with vendors, the vendor provides a variety of modules and their implementation is limited by funding and service priority. As well as problems in the system, namely privacy leaks, quite high costs for first time preparation and maintenance, and there are obstacles in unclear government policies, and lack of standardization of data between vendors, so interoperability cannot be implemented.

The benefits obtained from implementing this interoperable system according to (Rac, et al, 2019) (Wen, et al, 2019) are by using medical data standards, with the same structure, then: 
1. make it easier for doctors in medical services, to reduce the possibility of forgetting the information needed to make a proper diagnosis by doctors and avoid medical errors

2. Having the ability to reduce health customer costs by using existing medical information, no need for re-examination

3. Prevent repeated examination and treatment

4. Reducing health expenses

5. Produce an effective exchange of information.

6. Completion and continuous updating of medical information in real time after the patient's doctor consultation, automatically stored in the database

7. Share medical data in the system, make it easier when patients need it

8. And the hospital can make reports easily.

\section{Discussion}

The Healthcare Information and Management Systems Society (HIMSS, 2013) defines interoperability as the ability of information technology systems and different software applications to communicate, exchange data, and use previous information. This means that health information systems can work together within and across organizational boundaries to increase effective health care delivery to individuals and communities. According to HIMSS (2014) comprehensive electronic medical records are the basis of high-quality care, so doctors need them to make and record clinical decisions as well as software, medical devices, and IT systems used in health care organizations are often incompatible, thus sharing patient data becomes difficult, time consuming, and expensive. So this becomes an obstacle in implementing interoperable systems.

Why is this interoperability system necessary? According to the European Commission (Commision European, 2012) estimated using an open standardization to enable interoperability systems will save $€ 1$ billion in the EU public sector annually. So that the EC develops the European e-health interoperability framework for supporting work in its member. In accordance with Rac-albu (2019) there were several things benefited in its application, namely reducing health costs and increasing the efficiency of medical and administrative personnel.

According to Rac-albu (2015), there was a requirement to implement this system, namely the hospital had an integrated EMR, for medical data exchanged, both had the same data standards in collecting medical records so that an interoperable system or data exchange could be carried out. Without standardization, interoperability is impossible. In accordance with the research of Wen, et al (2019) in Taiwan, preparation for interoperable was having an EMR that could be exchanged and adopted the same standard for clinical documents. HIMSS (2019) divided 4 standardization of medical data, namely:

- Standard content: medical documents, data content in the exchange of information. The structure and organization of the document's electronic message content. Examples of these standards are HL7 (Health Level Seven) v2 and HL7-CDA (Clinical Document Architecture).

- Transport standards: the format of messages exchanged between different computer systems. Examples: HL7, HL7-FHIR (Fast Healthcare Interoperability Resources) and DICOM (Digital Imaging and Communications in Medicine).

- Standard terminology: based on a series of codes, qualification systems, structural vocabulary and terminology used in the medical field. Examples: LOINC (Logical Observation Identifiers Names and Codes), SNOMED-CT (Systematized Nomenclature of Medicine-Clinical Terms), MEDCIN, ICD-9/10 (International Statistics Classification of Diseases and Related Health Problems), RxNorm, etc.

- Safety and confidentiality standards: the protection of patient rights. Namely the HIPAA (Health Insurance Portability and Accountability Act) security rules and security standards (ISO, COBIT-Control Objectives for Information and Related Technologies). 
This data standardization is in accordance with (Oza et al, 2017) (Wang, et al, 2015) data standardization using SNOMED CT, ICD-10 and in accordance with HL-7 version 2 \& FHIR for Interoperable data, as for other data standards, namely HL- 7, CDA and DICOM.

The obstacles in implementing this system, according to HIMSSEU (2013) in Spain, the lack of expertise and difficulty in meeting the HL7 standard requirements were the main factors, 5.4\% were difficult to cooperate with vendors. In the United Kingdom, that is the technology and implementation of the system and the lack of expertise and internal resources in implementing the system, and $12.5 \%$ found it difficult to work with vendors. As well as in Germany, vendors were a major problem in implementing this system and data standardization was the second problem. This obstacle was in accordance with the results obtained, namely dividing the problem from the user, the vendor and the system.

According to Rac-albu (2019) getting interoperability in the medical field was not fully achieved in any country, some countries that have implemented it was still in various stages depending on the level of economic development and information of each country. For example, in several countries in continental Europe, such as Spain, Germany and the UK (HIMSS, 2014). In Europe, there were several variables drove the need for this system, namely population demographics, the completeness of health services and other operational factors such as cost, quality, safety and efficiency. And there were several layers, from the pan-European level to the national, regional, organizational, departmental and system levels. It needed the role of the government and the National Health Service (NHS) (HIMSS 2014). In accordance with (Muinga, et al, 2020) (Dovody, et al, 2019) worked with governments with top-down and bottom-up systems and the existence of clear regulations and policies.

\section{Conclusion}

The successful interoperability of digital information systems depends on the presence of exchange standards, data security, data adoption and supporting government regulation. Improving the coordination and interoperability of health record systems will facilitate access to the right information at the right time for millions of patients every year.

\section{Further Research}

Further research are expected to be able to assess the impact of implementing interoperability on health information systems in terms of financial, data security, and clinical impacts of interoperability.

\section{Limitation of Study}

This research has limitations considering that it uses a qualitative systematic review method with only two authors in analyzing articles. According (Bettany-Saltikov, 2010) Systematic review must be carried out by a group of researchers, while according to (Bettany-Saltikov, 2010), one researcher can also examine systematic review by following the recommended guidelines. The second limitation is interoperability in the health information system between hospitals and other service facilities are still not running well in developing countries, so it still difficult to implement it.

\section{Conflict of Interest}

This research does not conflict with anyone's interest. 


\section{References}

Alarakhia, M., Barker, P., Brisson, M., Graham, T., Grimm, C., Lee, T., ... Vermeer, K. (2018). Connected Health Information in Canada: A Benefits Evaluation Study. Canada Health Infoway, (April), 27. Retrieved from https://www.infoway-inforoute.ca/en/component/edocman/3510-connected-health-info

Bae, Y. S., Kim, K. H., Choi, S. W., Ko, T., Jeong, C. W., Cho, B. L., ... Kang, E. K. (2020). Information Technology-Based Management of Clinically Healthy COVID-19 Patients: Lessons From a Living and Treatment Support Center Operated by Seoul National University Hospital. Journal of Medical Internet Research, 22(6), e19938. https://doi.org/10.2196/19938

Bettany-Saltikov, J. (2010). Learning how to undertake a systematic review: Part 2. In Nursing standard (Royal College of Nursing (Great Britain) : 1987) (Vol. 24, Issue 51). https://doi.org/10.7748/ns2010.08.24.51.47.c7943

Commision European. (2012). Digital Agenda : Open Standards would save public save public sector $€ 1$ billion a year. Brussels. 25th June 2012. Downloaded : 10th December 2020. https://ec.europa.eu/commission/presscorner/detail/en/IP 13 602

Davoody, N., Koch, S., Krakau, I., \& Hägglund, M. (2019). Accessing and sharing health information for postdischarge stroke care through a national health information exchange platform - A case study. BMC Medical Informatics and Decision Making, 19(1), 1-16. https://doi.org/10.1186/s12911-019-0816-X

Dobrow, M. J., Bytautas, J. P., Tharmalingam, S., \& Hagens, S. (2019). Interoperable Electronic Health Records and Health Information Exchanges: Systematic Review. JMIR Medical Informatics, 7(2), e12607. https://doi.org/10.2196/12607

Healthcare Information and Management Systems Society (HIMSS). (2013, April 5). Definition of interoperability. Retrieved from http://www.himss.org/sites/himssorg/files/FileDownloads/HIMSS\%20 Interoperability\%20Definition\%20FINAL.pdf.

HIMSS. (2014). Strategic Interoperability in Germany, Spain \& the UK. The Clinical Business Imperative,. Retrieved from http://www.himss.eu/sites/default/files/HIMSSEU_WhitePapers_InterSystems.pdf

HIMSS. (2019). Interoperability \& Health Information Exchange. https://www.himss.org/interoperability-andhealth-information-exchange

Kanakubo, T., \& Kharrazi, H. (2019). Comparing the Trends of Electronic Health Record Adoption Among Hospitals of the United States and Japan. Journal of Medical Systems, 43(7). https://doi.org/10.1007/s10916-0191361-y

Muinga, N., Magare, S., Monda, J., English, M., Fraser, H., Powell, J., \& Paton, C. (2020). Digital health Systems in Kenyan Public Hospitals: A mixed-methods survey. BMC Medical Informatics and Decision Making, 20(1), 1-15. https://doi.org/10.1186/s12911-019-1005-7

Oza, S., Jazayeri, D., Teich, J. M., Ball, E., Nankubuge, P. A., Rwebembera, J., ... Fraser, H. S. (2017). Development and deployment of the OpenMRS-Ebola electronic health record system for an Ebola treatment center in Sierra Leone. Journal of Medical Internet Research, 19(8). https://doi.org/10.2196/jmir.7881

Poba-Nzaou, P., Kume, N., \& Kobayashi, S. (2020). Developing and Sustaining an Open Source Electronic Health Record: Evidence from a Field Study in Japan. Journal of Medical Systems, 44(9). https://doi.org/10.1007/s10916$\underline{020-01625-3}$

Rac-albu, M. E. (2015). IINTEROPERABILITY OF MEDICAL DATA FROM CONCEPT TO APPLICATION. (6), 164-177.

Rac-Albu, M. M.-E., \& Rac-Albu, M. M.-E. (2019). A Model of Achieving Safe Interoperability of Medical Data in the Private Sector of Health Care in Romania. Informatica Economica, 23(3), 84-95. https://doi.org/http://dx.doi.org/10.12948/issn14531305/23.3.2019.08

Shull, J. G. (2019). Digital health and the state of interoperable electronic health records. Journal of Medical Internet Research, 21(11), 1-8. https://doi.org/10.2196/12712 
Wang, J., Ho, H., Chen, J., Chai, S., Tai, C., \& Chen, Y. (2015). Attitudes toward inter-hospital electronic patient record exchange : discrepancies among physicians, medical record staff, and patients. BMC Health Services Research, (666), 1-15. https://doi.org/10.1186/s12913-015-0896-y

Warren, L. R., Clarke, J., Arora, S., \& Darzi, A. (2019). Improving data sharing between acute hospitals in England: an overview of health record system distribution and retrospective observational analysis of interhospital transitions of care. BMJ Open, 9(12). https://doi.org/http://dx.doi.org/10.1136/bmjopen-2019-031637

Wen, H.-C., Chang, W.-P., Hsu, M.-H., Ho, C.-H., \& Chu, C.-M. (2019). An Assessment of the Interoperability of Electronic Health Record Exchanges Among Hospitals and Clinics in Taiwan. JMIR Medical Informatics, 7(1), e12630. https://doi.org/10.2196/12630

WHO, Organization, W. H., \& WHO. (2013). eHealth standardization and interoperability. Sixty-Sixth World Health Assembly Wha66.24, (May), 1-3. Retrieved from citeulike-articleid:12416934\%0Ahttp://apps.who.int/gb/ebwha/pdf_files/EB132/B132_R8-en.pdf?ua=1 